Jamal Academic Research Journal-an Interdisciplinary- ISSN: 2582-5941

S. Revathi JARJ-Vol-1-1-FEB-2020:12-19

Jamal Academic Research Journal : An Interdisciplinary

(Run by Jamal Mohamed College, Tiruchirappalli)

\title{
STUDY GROWTH AND CHARACTERIZATION OF CHLORIDE DOPED POTASSIUM DIHYDROGEN ORTHOPHOSPHATE CRYSTAL
}

\author{
S. Revathi* \\ *Department of Physics, Annai Women's College, Karur - 639 136, Tamil Nadu, India
}

\begin{abstract}
Potassium dihydrogen phosphate (KDP) crystal has been doped with chloride to alter its physical and chemical properties. The pure and chloride mixtured KDP was grown by slow evaporation solution growth technique. The X-raydiffractometry (XRD) analys is shows that the crystalline perfection these optimum conditions is extremely good without having any internal structural grain boundaries and mosaic nature. The lattice parameters have been determined for pure KDP and chloride mixtured KDP from the single crystal XRD. The crystals grown by these optimum conditions show positive effects in the various characterization techniques.
\end{abstract} Key words: KDP crystal, solution growth, XRD.

Corresponding Author E-mail: revathiadsaya@gmail.com

\section{Introduction}

Materials with large optical nonlinearity are needed to realize applications in optoelectronics, telecommunication industries, laser technology, and optical storage devices. ADP and KDP are two of the oldest crystals grown in large size for many applications and continue to be interesting materials the aim of improving the SHG efficiency of KDP, researchers have attempted to modify KDP crystals both academically and industrially. Potassium dihydrogen phosphate (KDP) is an excellent inorganic nonlinear optical (NLO) material and has a considerable interest amongst several research workers because of its wide frequency, high efficiency of frequency conversion, and high damage threshold against high power laser. With either by doping different type of impurities or by changing the growth conditions [1-9]. 
The adjustment effect of additives on the growth process and properties of crystals has been applied in recent years [10-12]. With additives, KDP crystals can be grown rapidly in the traditional crystallizers of simple design for conventional growth. In this present work, KDP crystals were grown from the aqueous solutions added with $1 \mathrm{M} \% \mathrm{KCl}$ and allowed to growth by optimum conditions.

\section{Experimental Procedure}

Pure KDP single crystal was grown by taking potassium dihydrogen phosphate and hydrochloric acid in 1:1 normality ratio. The calculated amount of potassium dihydrogen phosphate was taken in a beaker. The potassium dihydrogen salt was dissolved water. The calculated amount of hydrochloric acid is added slowly in the walls of the beaker containing aqueous solution of potassium dihydrogen phosphate. The resultant solution was stirred about 2 hours. The solution was heated about $40^{\circ} \mathrm{C}$. Finally the solution was filtered.

\subsection{Growth Of Chloride Doped KDP Single Crystal}

At first the solution was filtered to remove insoluble impurities. Then the supersaturated solution was covered by using a ordinary paper with perforations. Minimum number of holes were made (7-10) in the ordinary paper to control the evaporation. Then the solution was kept at room temperature in an undisturbed place for slow evaporation. After 4 days, the regular shaped crystal was harvested from the solution. The grown crystal as shown in Figure 1.

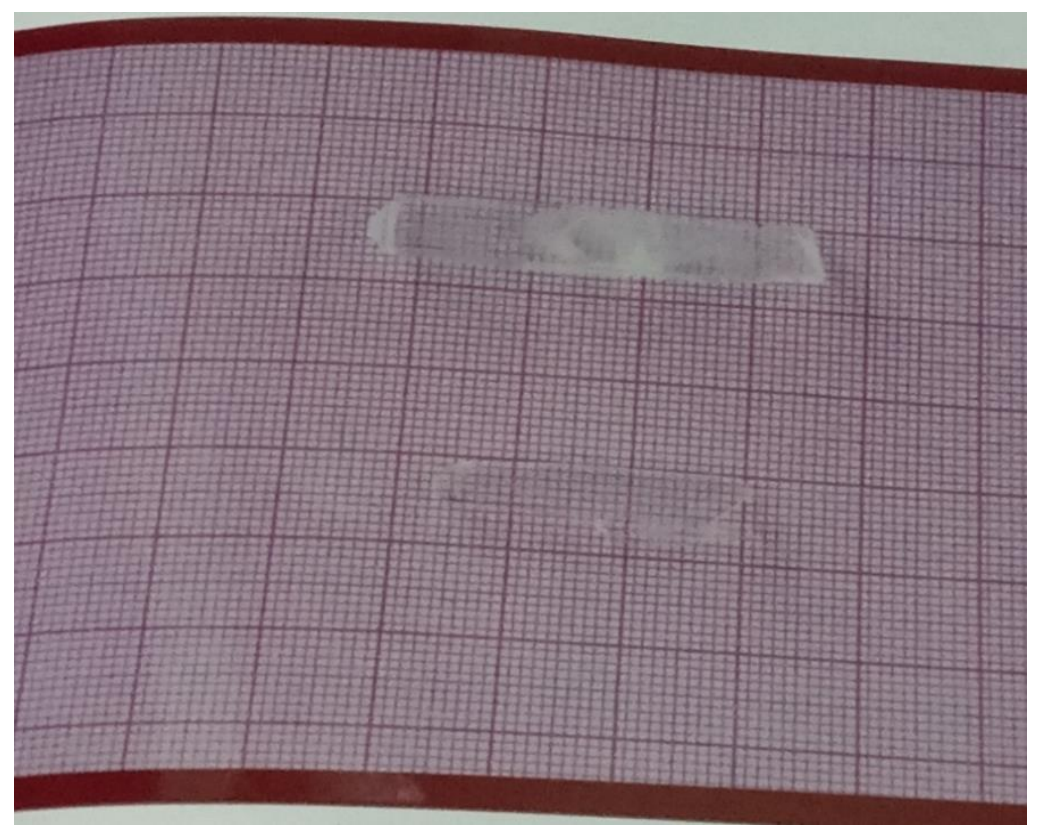

Fig. 1 Chloride doped KDP single crystal grown from slow evaporation method 


\section{Characterizations}

The grown Sacrosine doped KDP crystals were subjected to various characterizations. Single crystal $\mathrm{X}$-ray diffraction studies were carried out using single crystal diffractometer ENRAF NONIUS Cad4 and its lattice parameter volume structure and space group is analyzed in given in table. Powder X-ray diffraction studies were carried out using powder Xray diffraction instrument D8 advanced BRUKER Spectrometer using $\mathrm{CuK} \alpha$ radiation source and its wave length $(\lambda=1.54 \AA$ ) , data collected from the $2 \theta$ range from $10^{\circ}$ to $90^{\circ}$ in steps of 0.020 and count time $0.2 \mathrm{~S}$. Identification of functional groups was carried out by FTIR analysis using JASCO 4100. UVVisible spectral study is carried out using SHIMADZU 2600 in the range 200-1200nm. The flat surface of the LPKDP crystal were subjected to the hardness measurements using Leitz-Weitzlar hardness tester fitted with a Vicker's diamond indenter.

\section{Results and Discussion}

\subsection{FTIR Analysis}

The FTIR analysis of chloride doped KDP was carried out to investigate the presence of functional groups and their vibrational modes. The FTIR spectrum was recorded between the frequencies 400 and $4000 \mathrm{~cm}^{-1}$ using spectrum RXI spectrometer and the spectrum is shown in the Figure 2 and the assignment values are tabulated in table 1 . The $(\mathrm{OH})$ stretching mode is observed at $3780 \mathrm{~cm}^{-1}$. The $(\mathrm{OH})$ symmetric vibration mode is observed at $3417 \mathrm{~cm}^{-1}$. The bands are observed at $2828 \mathrm{~cm}^{-1}$, and $2453 \mathrm{~cm}^{-1}$ are due to contribution and overtones. The $(\mathrm{P}=\mathrm{O})$ asymmetric mode is observed at $1600 \mathrm{~cm}^{-1}$. The $(\mathrm{P}=\mathrm{O})$ symmetric mode is observed at 1302 $\mathrm{cm}^{-1}$. The (P-O) asymmetric mode is observed at $1094 \mathrm{~cm}^{-1}$. The (P-O) symmetric mode is observed at $914 \mathrm{~cm}^{-1}$.

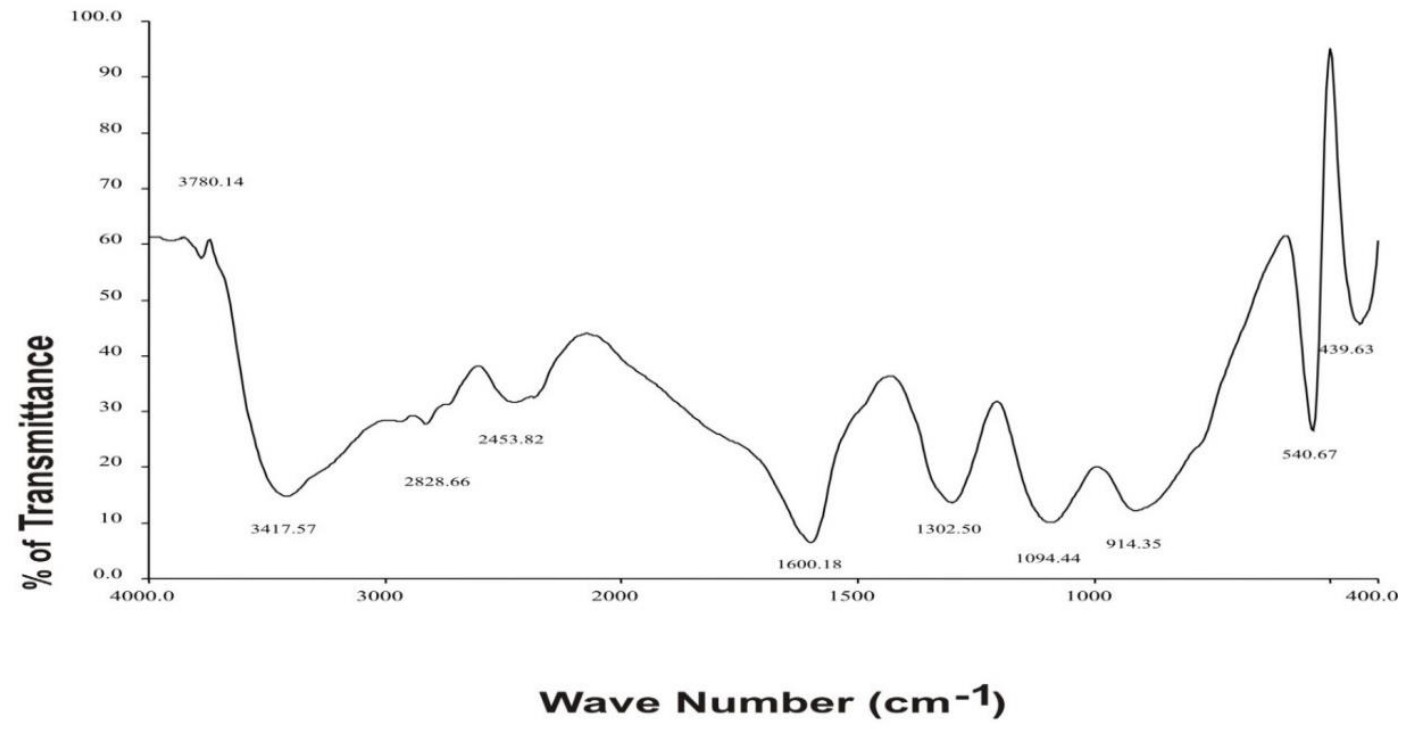

Fig. 2. FTIR spectrum of chloride doped KDP single crystal 
The (O- P-O) stretching mode is observed at $540 \mathrm{~cm}^{-1}$. The deformation mode is observed at $439 \mathrm{~cm}^{-1}$ [13].

\subsection{UV- Vis -NIR Spectral Analysis}

The optical transmittance spectra of chloride doped KDP single crystal was recorded in the range 190 -1100 nm using LAMBDA- 35 UV-VIS-NIR spectrometer. The Figure 3(a) shows that the UVVIS -NIR spectrum of chloride doped KDP single crystal. The graph is drawn between transmittance against wavelength the cut off wavelengths are 320 $\mathrm{nm}$ for chloride doped KDP crystal grown from aqueous solution. It is clean from the transmittance spectrum that the crystal is well transparent throughout the entire visible region. The large transmission in the entire visible region enables it to be a good candidate for electronic devices.

\section{Absorption spectrum}

The optical absorption spectrum of chloride doped KDP single crystal was recorded in the range
190- $1100 \mathrm{~nm}$ using LAMBDA- 35 UV-VIS NIR spectrometer. The Figure 3(b) shows that the UVVIS -NIR absorbance spectrum of chloride doped KDP single crystal.

From the absorbance spectrum, the cut off frequency is noted at $200 \mathrm{~cm}^{-1}$. There is no absorbance throughout the entire region because the phosphate anions do not absorb radiation significantly in UV-VIS-NIR region [14].

Table 1 FTIR frequency assignment for HCl mixed KDP

\begin{tabular}{|c|c|}
\hline Wave number & Tentative assignments \\
\hline 3780 & ( OH ) stretching \\
\hline 3417 & ( OH ) symmetric vibrations \\
\hline 2828 & Combination bands \\
\hline 2453 & Over tones \\
\hline 1600 & $(\mathrm{P}=\mathrm{O})$ Asymmetric stretching \\
\hline 1302 & $(\mathrm{P}=\mathrm{O})$ symmetric stretching \\
\hline 1094 & ( -O ) Asymmetric stretching \\
\hline 914 & ( $-\mathrm{O})$ symmetric stretching \\
\hline 540 & ( O-P-O ) stretching \\
\hline 439 & ( P-OH ) deformation \\
\hline
\end{tabular}

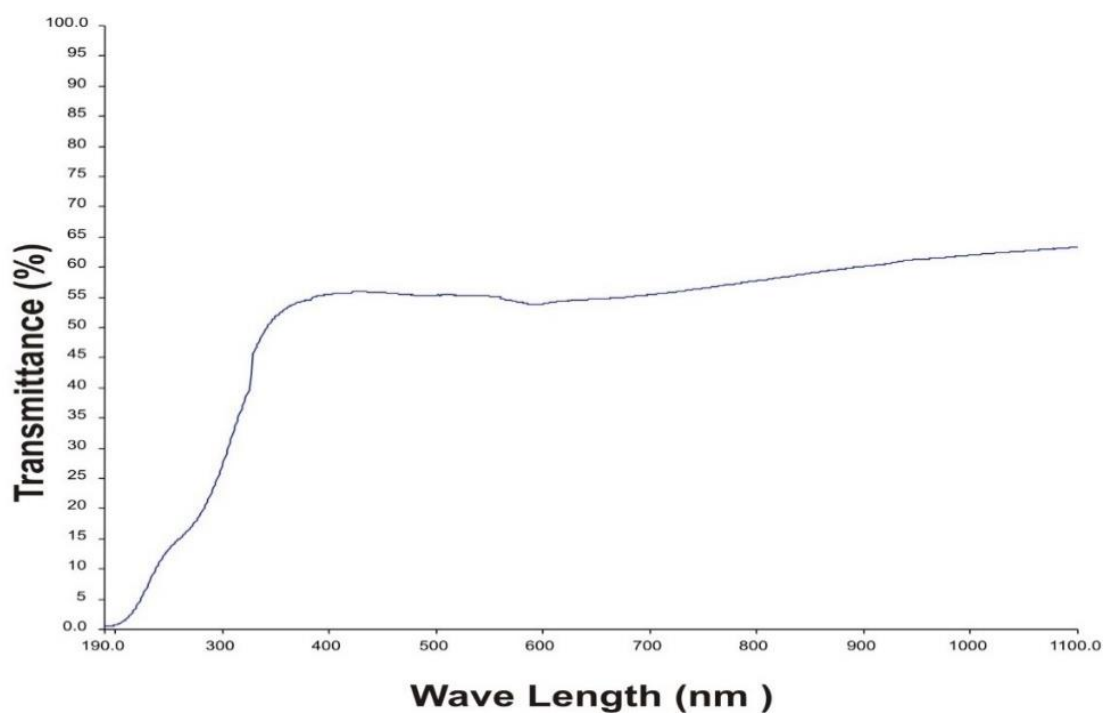

Fig. 3(a). UV-VIS -NIR Transmittance spectrum of chloride doped KDP single crystal 
Jamal Academic Research Journal-an Interdisciplinary

S. Revathi JARJ-Vol-1-1-FEB-2020:12-19

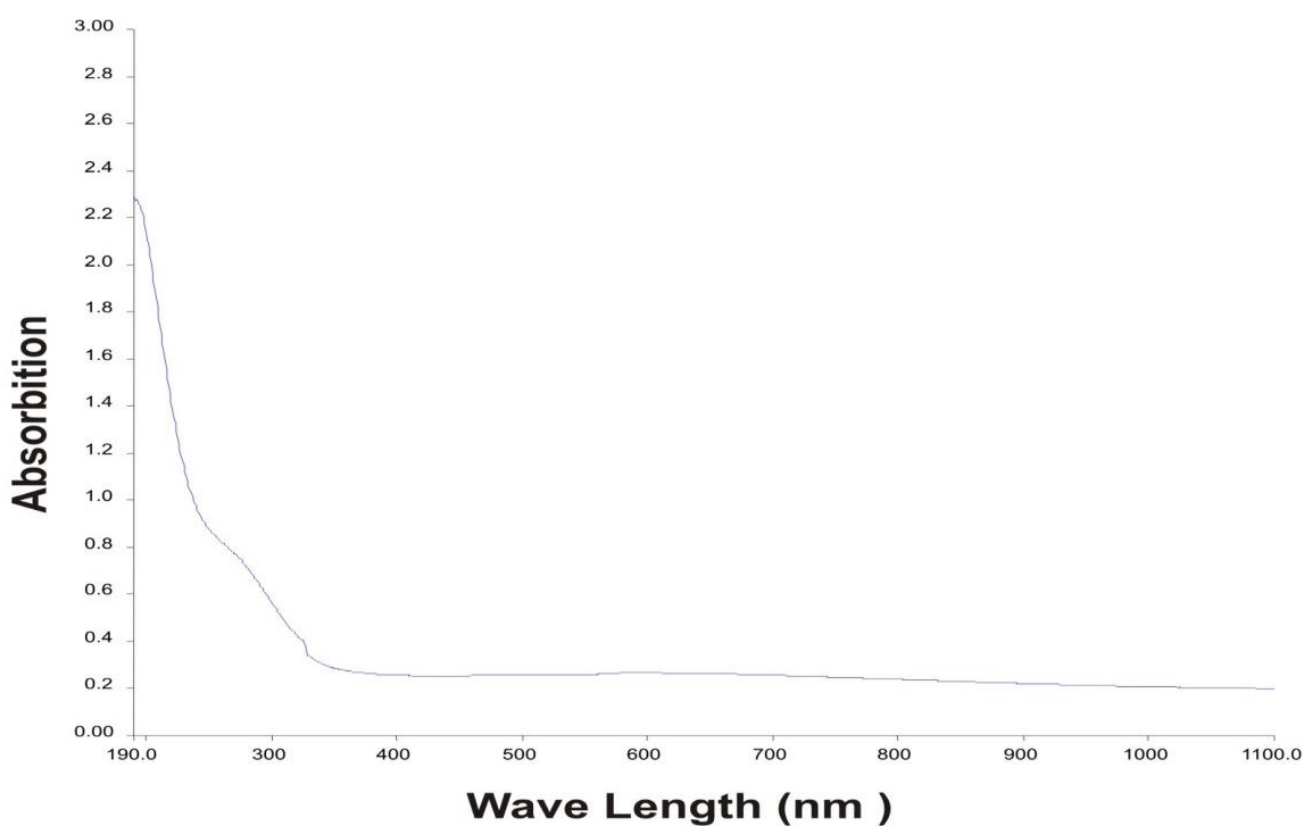

Fig. 3(b). UV-VIS -NIR Absorbition spectrum of chloride doped KDP single crystal

\subsection{X-ray Single Crystal Analysis}

\section{Cell dimension of chloride doped KDP crystal}

Single crystal X-ray diffraction study was carried out for chloride doped KDP single crystal using BRUKER- NONLUS CAD-4 diffract meter. Figure 4 shows that X-ray powder diffraction patterns for KDP crystals. Chloride doped KDP belongs to the Hexagonal crystal system. The cell parameters are

$$
\begin{gathered}
\mathrm{a}=6.316(1) \mathrm{A}^{\mathrm{o}}, \mathrm{b}=10.531(5) \mathrm{A}^{\mathrm{o}}, \\
\mathrm{c}=6.309(1) \mathrm{A}^{\mathrm{o}}, \alpha=90.00, \beta=113.02^{\circ}, \\
\gamma=90.00^{\circ} \text { and Volume }=386.2(2) \mathrm{A}^{\circ} 3
\end{gathered}
$$

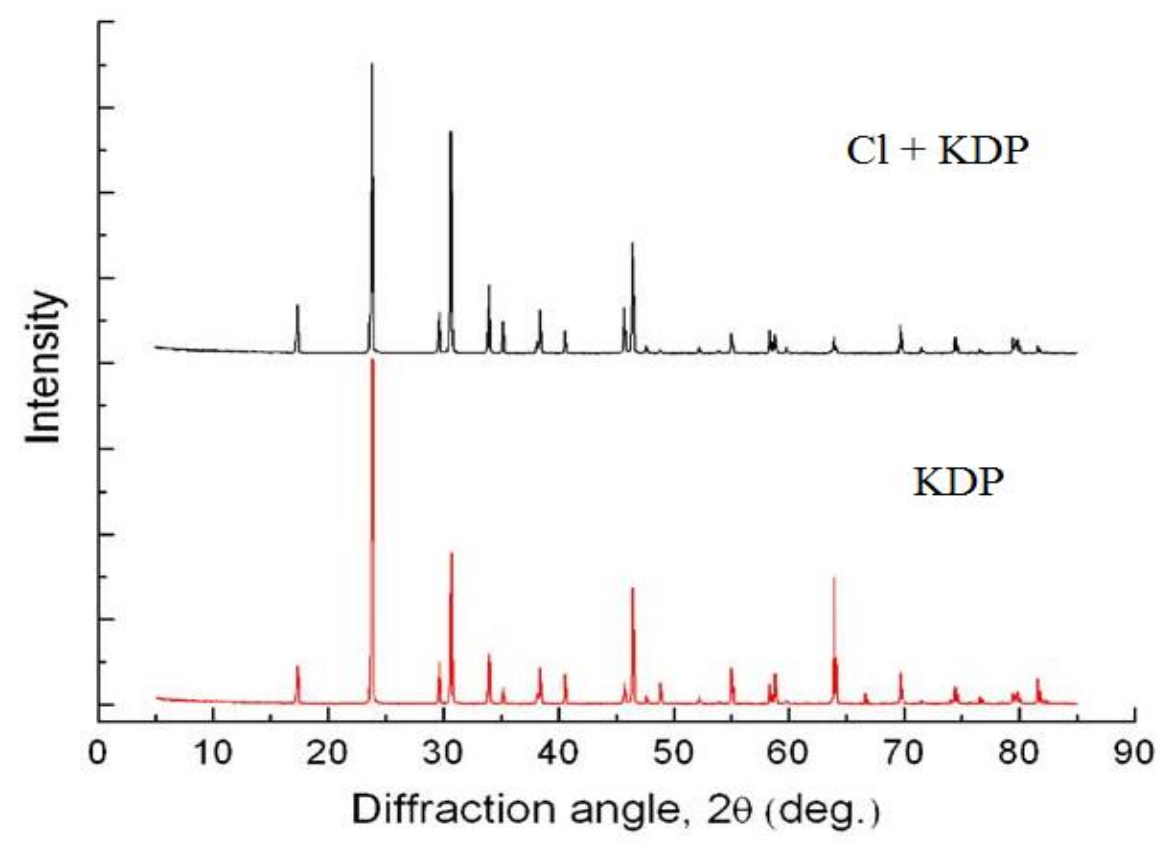

Fig. 4. X-ray powder diffraction patterns for KDP crystals. 


\subsection{Micro Hardness Studies}

Micro hardness of a crystal is its capacity to resist indentation. Physically hardness is the resistance offered by a material to the localized deformations caused by scratching or by indentations. Micro hardness and anisotropy study using Vickers micro hardness is one of the important deciding factors in selecting the processing (cutting, grinding and polishing) steps for bulk crystals during the fabrication of devices. Interpretation of hardness is perceived as ability of a material to resist permanent deformation [15].

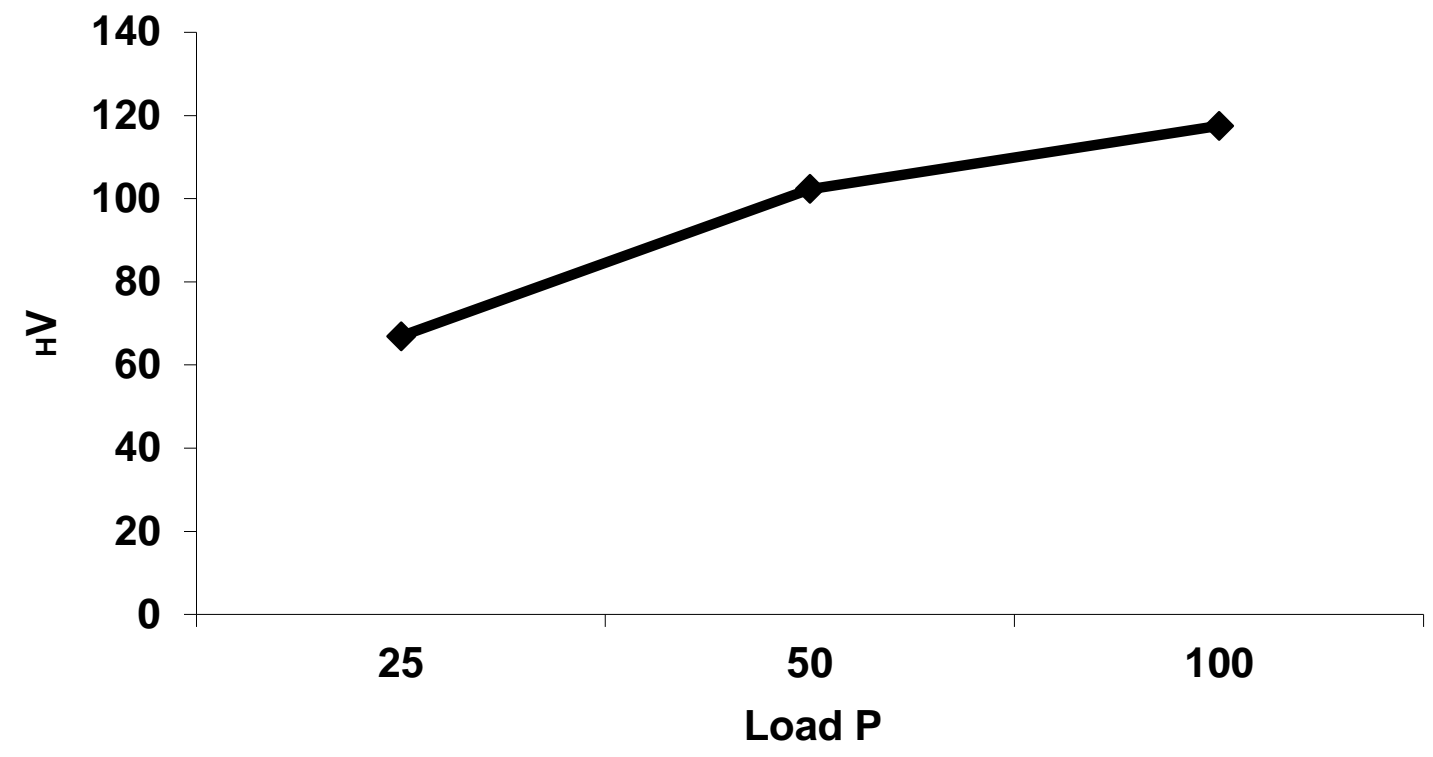

Fig. 5.1 Vickers Micro Hardness value Vs applied load for chloride doped KDP

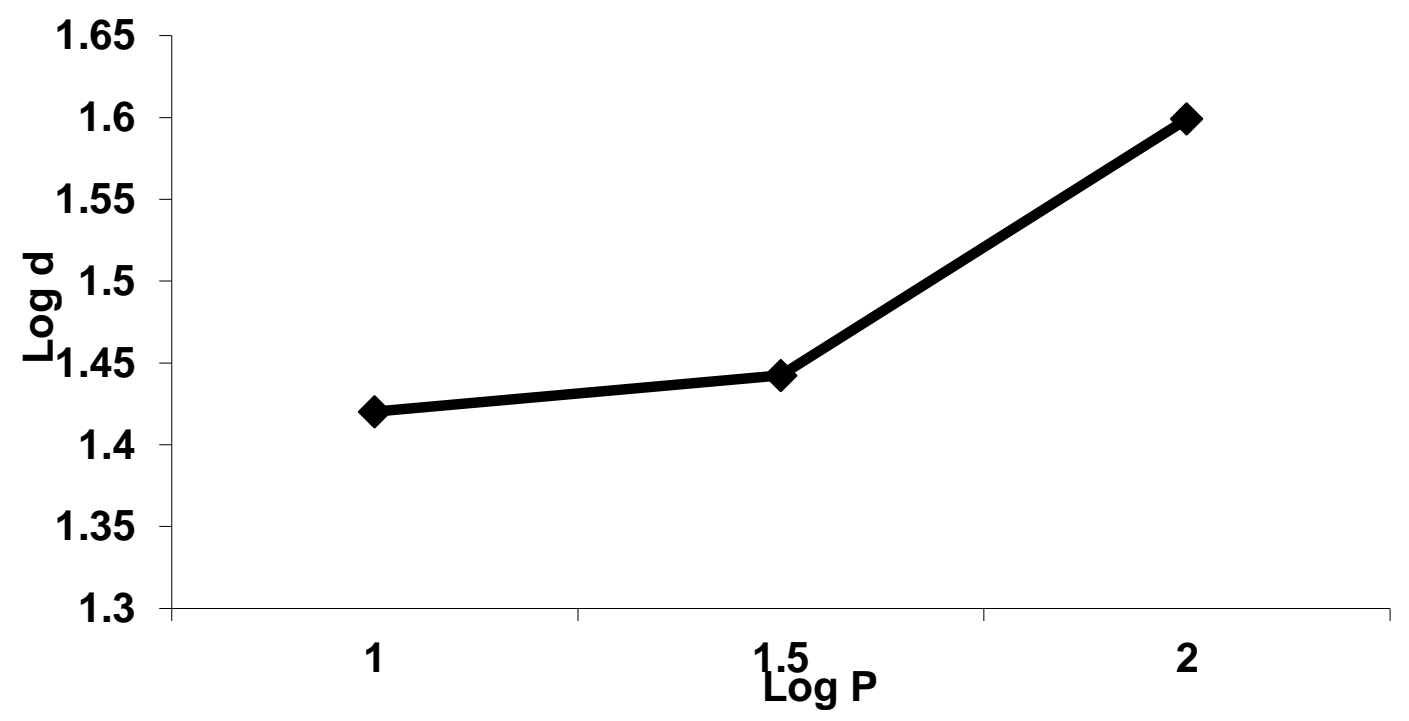

Fig.5.2 Log P Vs $\log d$ cure for chloride doped KDP single crystal 
Jamal Academic Research Journal-an Interdisciplinary

S. Revathi JARJ-Vol-1-1-FEB-2020:12-19

TABLE 2 MICRO HARDNESS OF CHLORIDE DOPED KDP SINGLE CRYSTALS

\begin{tabular}{|c|c|c|c|c|c|}
\hline S.NO & Load (P) & Length (d) & Hv & $\log (\mathbf{P})$ & $\log (\mathbf{d})$ \\
\hline 1 & 25 & 26.3125 & 66.9 & 1.3979 & 1.4202 \\
\hline 2 & 50 & 27.6925 & 102.3 & 1.6990 & 1.4424 \\
\hline 3 & 100 & 39.725 & 117.5 & 2.0000 & 1.5991 \\
\hline
\end{tabular}

Micro hardness measurement was carried out using square-based pyramidal diamond indenter having angle $136^{\circ}$ between opposite faces. The hardness measurements were made on the prominent plane of the crystal of thickness $0.3 \mathrm{~mm}$ using LeitzWeizler Vicker's hardness tester fitted with a Vickers diamond pyramidal indenter and attached to an incident light microscope. Loads ranging from 25 to $100 \mathrm{~g}$ were used for making indentations, keeping the time of indentation constant at 10s for all the cases.

The diagonal lengths of the indentation mark and crack length were measured, using the micrometer eyepiece at a magnification of X100.

$\mathrm{H}_{\mathrm{v}}=1.8544\left(\mathrm{P} / \mathrm{d}^{2}\right) \quad \mathrm{N} / \mathrm{m}^{2}$

Where $\mathrm{H}_{\mathrm{v}}$ is the Vickers hardness number, $\mathrm{P}$ is the applied load in $\mathrm{kg} / \mathrm{mm}^{2}$ and $\mathrm{d}$ is the average diagonal length of the impression observed in $\mathrm{mm}$. Load Vs Hv curves are shown in figure 5.1.

The nonlinear behaviour of the micro hardness of the crystal differs from one plane to another which confirms the micro hardness anisotropy.

Initially the hardness value increases with increasing the applied load. $\log \mathrm{P}$ Vs $\log \mathrm{d}$ curves are plotted (figure 5.2).

The work hardening coefficient ' $n$ ' is calculated form the equation $\mathrm{F}=\mathrm{a} \mathrm{d}^{\mathrm{n}}$.
Here $\mathrm{n}$ is the Meyer's index (or) Work Harding co-efficient has been calculated from the slope of the straight line. The value of $n$ is 2.6666.The calculated micro hardness values are presented in table 2 .

\section{Conclusion}

The pure and chloride admixtured KDP was grown by slow evaporation solution growth technique. The lattice parameters have been determined for pure KDP and chloride admixtured KDP from the single crystal X-ray diffraction .The pure KDP belongs to tetragonal crystal system and chloride admixtured KDP belongs to hexagonal crystal system .Transparencies of these crystals were found using UV -VIS-NIR transmittance spectra and it has good transmittance window .The functional groups of these crystals were identified using Fourier Transform Infrared Spectra. The micro hardness studies performed on pure KDP and chloride admixtured KDP indicates that Vickers hardness number increases with increase of load.

\section{References}

[1] K. D. Parikh, D. J. Dave, B. B. Parekh, and M. J. Joshi, "Thermal, FT-IR and SHG efficiency studies of L-arginine doped KDP crystals," Bulletin of Materials Science, vol. 30, no. 2, pp. 105-112, 2007. 
[2] K. D. Parikh, D. J. Dave, B. B. Parekh, and M. J. Joshi, "Growth and characterization of L-alanine doped KDP crystals," Crystal Research and Technology, vol. 45, no. 6, pp. 603-610, 2010.

[3] N. Vijayan, S. Rajasekaran, G. Bhagavannarayana et al., "Growth and characterization of nonlinear optical amino acid single crystal: L-Alanine," Crystal Growth and Design, vol. 6, no. 11, pp. 2441-2445, 2006.

[4] K. Ozga, V. Krishnakumar, I. V. Kityk, and J. Jasik- ' Slezak, "l-lysine monohydrochloride dihydrate as novel elasto- and electrooptical materials," Materials Letters, vol. 62, no. 30, pp. 4597-4600, 2008.

[5] V. Krishnakumar, R. Nagalakshmi, S. Manohar et al., "Elastooptical spectra of novel L-lysine monohydrochloride dehydrate single crystals," International Journal of Modern Physics B, vol. 24, no. 5, pp. 629-645, 2010.

[6] P. V. Dhanaraj, N. P. Rajesh, P. Ramasamy, M. Jeyaprakasan, C. K. Mahadevan, and G. Bhagavannarayana, "Enhancement of stability of growth, structural and NLO properties of KDP crystals due to additive along with seed rotation," Crystal Research and Technology, vol. 44, no. 1, pp. 54-60, 2009.

[7] P. P. Kumar, V. Manivannan, P. Sagayaraj, and J. Madhavan, "Growth and characterization of pure and doped NLO Larginine acetate Single crystals," Bulletin of Materials Science, vol. 32, no. 4, pp. 431435, 2009.

[8] B. S. Kumar and K. R. Babu, "Effect of Larginine, L-histidine and glycine on the growth of KDP single crystals and their characterization," Indian Journal of Pure and Applied Physics, vol. 46, no. 2, pp. 123-126, 2008.

[9] A. Rahman and J. Podder, "Effect of EDTA on the growth kinetics and structural and optical properties of KDP crystal," International Journal of Optics, vol. 2010, Article ID 978763, 5 pages, 2010. [10] Yang Shangfeng, Su Genbo, Li Zhengdong, Jiang Rihong, Journal of Crystal Growth vol. 197, pp. 383, 1999.

[11] T. Sasaki, A. Yokotani, Journal of Crystal Growth, vol. 99, pp. 820, 1990.

[12] A. Yokotani, H. Koide, T. Sasaki, T. Yamanaka, Journal of Crystal Growth vol. 67, pp. 627, 1984.
[13] P.Jagdish, N.P. Rajesh, Journal of Optoelectronis and Advance materials, "Effect of LProline on the Growth and NLO properties of KDP Crystals", Vol.13, No.8 962-966, 2011.

[14] S. Boomadevi, H. P. Mittal, and R. Dhansekaran, "Synthesis, crystal growth and characterization of 3-methyl 4- nitropyridine 1-oxide (POM) single crystals," Journal of Crystal Growth, vol. 261, no. 1, pp. 55-62, 2004.

[15] K. Jagannathan, S. Kalainathan, T. Gunasekaran, Materials Letters, Vol.61, pp. 4485, 2007. 